\title{
Capsule endoscopy for the diagnosis and follow-up of Crohn's disease: a comprehensive review of current status
}

\author{
Michael Dam Jensena, Jacob Broder Brodersen ${ }^{b}$, Jens Kjeldsenc \\ Lillebaelt Hospital Vejle; Hospital of Southwest Jutland, Esbjerg; Odense University Hospital, Odense, Denmark
}

\begin{abstract}
Capsule endoscopy (CE) has revolutionized the diagnosis and monitoring of small bowel Crohn's disease $(\mathrm{CD})$. The procedure is patient friendly and noninvasive, and compared to cross-sectional imaging, $\mathrm{CE}$ allows a direct and detailed evaluation of the entire small bowel mucosa with a high sensitivity for the earliest lesions of CD. Today, CE is the leading modality for visualizing the small bowel in suspected CD, and validated activity indices are available for the follow up of patients with established CD. CE of the entire gastrointestinal tract (panenteric CE) was recently introduced as a new diagnostic approach in patients examined for $\mathrm{CD}$, and preliminary results are promising. There are important limitations, involving mainly capsule retention. Furthermore, a diagnostic criterion for $\mathrm{CD}$ has never been validated, and lesions detected by $\mathrm{CE}$ are not specific for CD. Hence, concern has been raised about a low specificity compared to other diagnostic modalities. Important questions about the optimal bowel preparation, selection of patients for CE and the optimal reading protocol remain to be clarified. The aim of this review is to evaluate the performance of $\mathrm{CE}$ for diagnosing $\mathrm{CD}$ and assess disease activity in known $\mathrm{CD}$; to compare the diagnostic accuracy of $\mathrm{CE}$ to that of cross-sectional imaging; to discuss limitations; and to define the place of CE in the diagnostic algorithm in suspected or known CD.
\end{abstract}

Keywords Crohn disease, capsule endoscopy, diagnosis

Ann Gastroenterol 2017; 30 (1): 1-11

\section{Introduction}

Before the era of capsule endoscopy (CE), the small bowel was considered inaccessible and difficult to examine. Endoscopic evaluation of the small bowel was limited to the most distal or proximal part, with ileocolonoscopy and push enteroscopy, respectively, or in selected cases intraoperative enteroscopy, all of which are invasive procedures requiring conscious sedation or general anesthesia [1]. Although radiological procedures such as magnetic resonance enterography (MRE) and ultrasound have improved, they mainly visualize the transmural gut inflammation and have limited sensitivity for superficial lesions [2,3]. Since its FDA approval in 2001, CE has

Departments of anternal Medicine, Section of Gastroenterology, Lillebaelt Hospital Vejle (Michael Dam Jensen); ' Internal Medicine, Section of Gastroenterology, Hospital of Southwest Jutland, Esbjerg (Jacob Broder Brodersen); 'Medical Gastroenterology, Odense University Hospital, Odense (Jens Kjeldsen), Denmark

Conflict of Interest: None

Correspondence to: Michael Dam Jensen, MD, PhD, Department of Internal Medicine, Section of Gastroenterology, Lillebaelt Hospital Vejle, Kabbeltoft 25, 7100 Vejle, Denmark, Tel.: +45 7940 6345, Fax: +45 7940 6887, e-mail: michael.dam.jensen@rsyd.dk

Received 19 October 2016; accepted 17 November 2016; published online 22 December 2016

DOI: https://doi.org/10.20524/aog.2016.0119

๑) 2017 Hellenic Society of Gastroenterology revolutionized small bowel imaging and important knowledge has been gained about its clinical use. The main indications for $\mathrm{CE}$ are obscure gastrointestinal bleeding, suspected Crohn's disease (CD), assessment of disease activity, mucosal healing and disease location in known $\mathrm{CD}$, and discrimination between $\mathrm{CD}$ and ulcerative coliti s [4-6]. Other indications may include celiac disease, small bowel tumors, non-steroid anti-inflammatory drug (NSAID) enteropathy, or polyposis syndromes. CE is a patient-friendly and noninvasive procedure and, compared to cross-sectional imaging, CE allows a direct and detailed evaluation of the entire small bowel mucosa with detection of the earliest lesions of CD [7]. However, there are important limitations, of which capsule retention is the main concern (Table 1) $[5,8,9]$.

The aim of this review is to evaluate the performance of CE for diagnosing $\mathrm{CD}$ and assess disease activity in known $\mathrm{CD}$; to compare the diagnostic accuracy of $\mathrm{CE}$ to that of cross-sectional imaging; to discuss limitations; and to define the place of CE in the diagnostic algorithm in suspected or known CD.

\section{Materials and methods}

An extensive English-language literature search was conducted using PubMed to identify peer-reviewed original and review articles, using the keywords "capsule endoscopy", “suspected or known Crohn's disease, "bowel 
cleansing", "activity index", "mucosal healing", "C-reactive protein", "fecal calprotectin”, "ileocolonoscopy”, "magnetic resonance imaging", "computed tomography", "ultrasound", "postsurgical recurrence", "capsule retention", "quick view", "Pillcam colon", and "panenteric capsule endoscopy". The references of selected studies were searched manually to identify additional relevant studies. Systematic reviews and meta-analyses of randomized controlled trials were considered the highest level of evidence (www.cebm.net). Studies of diagnostic accuracy were reviewed in accordance with the QUADAS tool for quality assessment of diagnostic accuracy studies [10].

\section{CE systems}

There are currently five CE systems available for visualizing the small bowel: Pillcam SB3 (Medtronic, Dublin, Ireland),
EndoCapsule EC-S10 (Olympus, Tokyo, Japan), MiroCam MC-1000W (Intromedic, Soul, South Korea), OMOM (Jinshan Science and Technology, Chongqing, China), and CapsoCam SV3 (CapsoVision, Saratoga, USA) [11]. Furthermore, the Pillcam COLON2 (Medtronic, Dublin, Ireland) visualizes the small bowel, although it was designed for diagnosing the colon. Specifications provided by the manufacturers are shown in Table 2. Although CE systems are based on comparable technologies, important differences exist: e.g. the number of cameras, frame rate, angle of view, viewing direction, image resolution, and battery life. Theoretically, these differences could influence the diagnostic sensitivity for $C D$ and the rate of complete small bowel examinations. However, studies comparing different CE systems head-to-head in patients with suspected or known CD are currently not available. In CD, the majority of studies have been performed with the Pillcam SB1 and SB2, as this CE system has dominated the world market for years. In patients with obscure gastrointestinal bleeding, studies comparing Pillcam SB1 with EndoCapsule [12,13], Pillcam SB2 with MiroCam [14,15], Pillcam SB2 with CapsoCam [16],

Table 1 Advantages and limitations of small bowel capsule endoscopy (CE) in Crohn's disease (CD)

\begin{tabular}{ll}
\hline Advantages & Limitations \\
\hline Noninvasive & Risk of capsule retention in stricturing CD \\
\hline $\begin{array}{l}\text { Patient-friendly } \\
\text { Direct mucosal evaluation }\end{array}$ & Inability to take biopsies \\
$\begin{array}{l}\text { Significantly higher diagnostic yield for CD } \\
\text { compared to other modalities }\end{array}$ & Significant number of incomplete examinations* \\
Better visualization of the proximal small bowel compared to other modalities & Analysis is time-consuming \\
\hline
\end{tabular}

${ }^{{ }^{*} I n}$ a systematic review of 2295 CE's performed in suspected or known CD, a completion rate of $85 \%$ was reported [55]

Table 2 Specifications of available capsule endoscopy systems for examining the small bowel. The Pillcam COLON2 was designed for studying the colon but it also visualizes the small bowel

\begin{tabular}{|c|c|c|c|c|c|c|}
\hline Specifications & Medtronic & Medtronic & Olympus & Intromedic & $\begin{array}{l}\text { Jinshan science } \\
\text { and technology }\end{array}$ & CapsoVision \\
\hline $\begin{array}{l}\text { Capsule endoscopy } \\
\text { system }\end{array}$ & $\begin{array}{l}\text { Pillcam } \\
\text { SB3 }\end{array}$ & $\begin{array}{l}\text { Pillcam } \\
\text { COLON2 }\end{array}$ & $\begin{array}{l}\text { EndoCapsule } \\
\text { EC-S10 }\end{array}$ & $\begin{array}{l}\text { MiroCam } \\
\text { MC1000-W }\end{array}$ & $\begin{array}{l}\text { OMOM } \\
\text { JS-ME-II }\end{array}$ & $\begin{array}{l}\text { CapsoCam } \\
\text { Plus }\end{array}$ \\
\hline Size $(\mathrm{mm})$ & $26 \times 11$ & $32 \times 12$ & $26 \times 11$ & $25 \times 11$ & $28 \times 13$ & $31 \times 11$ \\
\hline Cameras (n) & 1 & 2 & 1 & 1 & 1 & 4 \\
\hline Viewing direction & Longitudinal & Longitudinal & Longitudinal & Longitudinal & Longitudinal & Lateral \\
\hline Weight (g) & 3.0 & 2.9 & 3.3 & 3.3 & 6.0 & 4.0 \\
\hline $\begin{array}{l}\text { Minimum battery } \\
\text { life }(\mathrm{h})\end{array}$ & 11 & 10 & 12 & 12 & 9 & 15 \\
\hline Image sensor & CMOS & CMOS & CMOS & CMOS & CMOS & CMOS \\
\hline $\begin{array}{l}\text { Frame rate } \\
\text { (frames/s) }\end{array}$ & $2-6$ & $4-35$ & 2 & 3 & 2 & $12-20$ \\
\hline Field of view $\left(^{\circ}\right)$ & 156 & 172 & 160 & 170 & 140 & 360 \\
\hline $\begin{array}{l}\text { Image } \\
\text { transmission }\end{array}$ & Radiofrequency & Radiofrequency & Radiofrequency & $\begin{array}{l}\text { Human body } \\
\text { communication }\end{array}$ & Radiofrequency & None $e^{* * *}$ \\
\hline
\end{tabular}

${ }^{* *}$ Data are transmitted to sensor electrodes on the skin using the human body as a conductor

${ }^{* *}$ Data are stored in the capsule in an onboard flash memory. The patient retrieves the capsule and returns it to the medical staff for data download

CMOS, complementary metal oxide semiconductor 
and EndoCapsule with MiroCam [17] found no significant differences in diagnostic yields.

\section{Small bowel cleansing}

Numerous studies have examined the effect of bowel cleansing regimens on mucosal visualization, diagnostic yield and completion rates, and results have been included in several systematic reviews and meta-analyses [18-21]. Original studies are heterogeneous in terms of included patients and scales used for determining the visualization quality. Results of individual studies are conflicting and meta-analyses have applied different inclusion criteria, with varying recommendations. In a meta-analysis of prospective randomized studies, including 291 patients who had polyethylene glycol (PEG) administered before CE and 232 controls, the small bowel visibility was significantly better with PEG (odds ratio [OR] 3.11; 95\% confidence interval [CI] 1.96-4.94), whereas no significant difference could be demonstrated between sodium phosphate treated patients and those on fasting only [21]. Overall, bowel cleansing increased the diagnostic yield compared to fasting alone (OR 1.88; 95\% CI 1.24-2.84). Simethicone improves the mucosal visualization but the effect on diagnostic yield remains to be established [22]. Prokinetics do not seem to affect the small bowel CE completion rate [20]. Hence, the current evidence suggests a bowel cleansing regimen containing PEG and simethicone before small bowel CE. However, additional studies on this matter are warranted. It should be emphasized that studies mainly included patients with obscure gastrointestinal bleeding and only a minority of patients were examined for CD. Whether bowel cleansing improves the mucosal visualization, diagnostic sensitivity and disease severity assessment in patients with CD is unknown. On the other hand, bowel cleansing causes discomfort, and currently, there is no consensus on the use of bowel cleansing before $\mathrm{CE}$ in patients examined for $\mathrm{CD}$.

\section{Suspected CD}

The cardinal lesions are mucosal ulcerations of varying severity (Fig. 1); in the earliest stage they present as aphthous ulcerations defined by a mucosal break with surrounding erythema. Punched out, linear or irregular ulcers with cobblestone appearance and stenosis caused by inflammation or fibrosis are seen in more severe CD. Other findings, such as erythema, edema and loss of villi without ulcerations, are considered non-specific [23]. It should be emphasized that ulcerations detected by $\mathrm{CE}$ are not specific for $\mathrm{CD}$, and $\mathrm{CE}$ does not allow tissue sampling to support the diagnosis.

Lesions caused by NSAIDs are an important differential diagnosis, because these drugs are frequently used in the general population. It is well established that NSAIDs are associated with gastrointestinal ulcerations, bleeding and strictures, that lesions are visualized with $\mathrm{CE}$ and they can
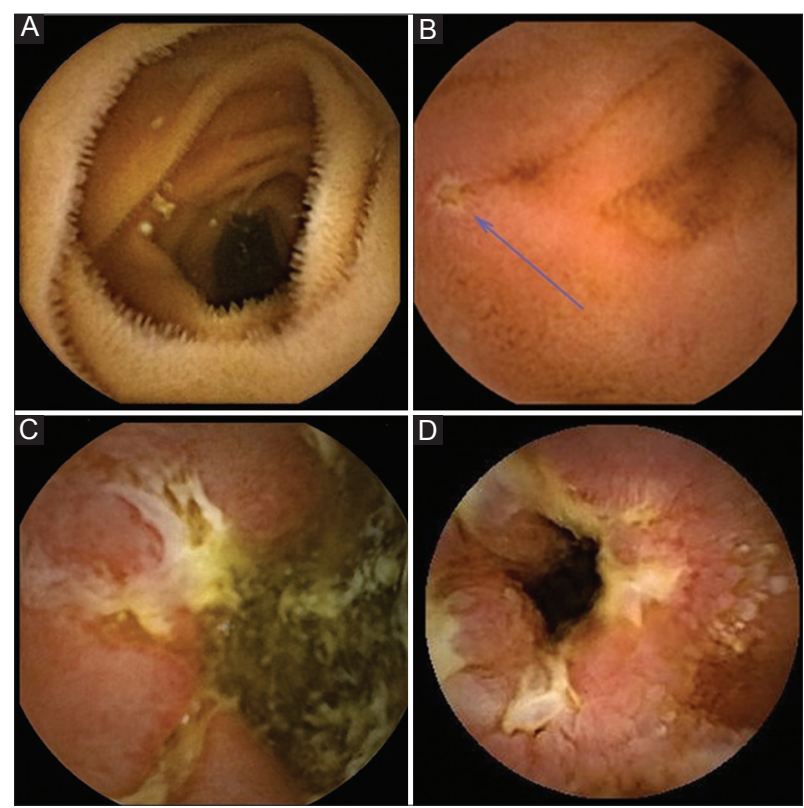

Figure 1 Crohn's disease of the small bowel detected with capsule endoscopy: (A) normal small bowel mucosa, (B) aphthous ulceration, (C) linear ulcers, and (D) ulcerated stenosis

mimic CD $[24,25]$. The precise number of weeks NSAIDs should be stopped prior to $\mathrm{CE}$ is unknown, but generally 4 weeks is recommended [8,26].

A surprising finding by Goldstein et al was that $11 \%$ of healthy volunteers who were not users of NSAIDs had mucosal breaks in the small bowel at a baseline CE [25]. In the subsequent clinical study, $7 \%$ of patients with a normal baseline CE developed 1-3 mucosal breaks after placebo treatment. This raises an important question about the diagnostic criterion and minimum threshold for diagnosing $\mathrm{CD}$ in patients examined with CE. At this point, no such criterion has been validated $[23,26]$. As suggested by Mow et al, the most frequently used diagnostic criterion for CD with $\mathrm{CE}$ is the presence of $>3$ ulcerations in patients not using NSAIDs [27].

Numerous studies have examined the clinical application of $\mathrm{CE}$ in patients with suspected or known CD. In the metaanalysis by Dionisio et al, the diagnostic yield of CE in patients with suspected $\mathrm{CD}$ was superior to that of small bowel radiography $(52 \%$ vs. $16 \%, \mathrm{P}<0.0001, \mathrm{n}=155)$, computed tomography enterography (CTE) $(68 \%$ vs. $21 \%, \mathrm{P}<0.0001$, $\mathrm{n}=53$ ) and ileocolonoscopy ( $47 \%$ vs. $25 \%, \mathrm{P}=0.009, \mathrm{n}=59$ ) [28]. Compared to MRE, CE had a higher diagnostic yield, but the difference did not reach statistical significance (55\% vs. $45 \%$, $\mathrm{P}=0.43, \mathrm{n}=31$ ). These results suggest that $\mathrm{CE}$ is the best modality for diagnosing small bowel CD. However, the lack of a gold standard comparison may lead to false conclusions, because false positive lesions count as true lesions and this tends to favor the most sensitive modality. Although the majority of studies have used multiple ulcerations as the diagnostic criterion for $\mathrm{CD}$, the diagnostic threshold differs between studies and some studies included non-specific lesions or the diagnostic criterion was not described [29-33]. In a 4-way comparison of CE, CTE, small bowel follow-through and ileocolonoscopy, 
the specificity of CE (53\%) was significantly lower compared to the other tests, supporting a high diagnostic yield because of false positive lesions [30]. A downside of this study, however, was that no criterion for diagnosing CD with CE was applied. A consensus gold standard based on the clinical presentation and results of all four modalities was used, but individual cases of disagreement were not discussed. Other prospective studies have compared $\mathrm{CE}$ with varying gold standards, showing a high sensitivity and specificity of CE for diagnosing CD (Table 3) [7,29,34].

\section{Selecting patients for CE}

To increase the diagnostic yield and avoid unnecessary diagnostic procedures, related expenses and patient discomfort, careful selection of patients for CE is of great importance. Relevant decision tools in this regard are biomarkers, fecal markers and the result of a preceding ileocolonoscopy.

A prospective study evaluated 72 patients with chronic abdominal pain with or without diarrhea and no explanation after ileocolonoscopy and upper endoscopy [35]. The diagnostic yield of CE was $67 \%$ and $21 \%$ in patients with or without increased markers of inflammation, respectively. A diagnosis of CD was obtained in $25 \%$ of patients, primarily in patients with abdominal pain, diarrhea and elevated markers of inflammation. Likewise, in a study by De Bona et al, CE detected lesions consistent with CD in $46 \%$ of patients with suspected CD and elevated biomarkers of inflammation compared to $8 \%$ in patients with normal biomarkers [36]. An elevated C-reactive protein (CRP) level has been shown to have sensitivity, specificity and positive predictive value of $73 \%$, $69 \%$ and $89 \%$, respectively, for diagnosing CD in the small bowel [37]. However, other studies have provided less favorable results. In a retrospective study of 189 patients with known small bowel CD, an elevated CRP was poorly associated with significant inflammatory lesions detected by CE, consistent with the body of evidence in general showing a suboptimal sensitivity of CRP for CD [38-40]. Hence, in patients with gastrointestinal symptoms suggestive of $\mathrm{CD}$ but a normal ileocolonoscopy, elevated markers of inflammation seem to be associated with an increased diagnostic yield of $\mathrm{CE}$, and in this situation CE should be considered. However, the sensitivity of $\mathrm{CRP}$ is inadequate and a normal value does not exclude small bowel CD.

Fecal calprotectin (fCal) is a highly sensitive marker of gastrointestinal inflammation, although it is not specific for inflammatory bowel disease. A normal value has a high negative predictive value and virtually excludes ileocolonic CD $[41,42]$. The utility of fCal for small bowel CD, however, has been debated. Some studies have reported lower levels of fCal in small bowel CD compared to CD involving the colon $[43,44]$, whereas other studies have found equal levels and a high sensitivity of fCal for small bowel CD [45]. Similarly, data on the ability of fCal to predict findings from CE have been conflicting. In a retrospective study by Koulaouzidis et al, $\mathrm{fCal}>100 \mathrm{mg} / \mathrm{kg}$ was a good predictor of small bowel CD detected with $\mathrm{CE}$ in patients with suspected $\mathrm{CD}$ but a negative bi-directional endoscopy, and fCal $<100 \mathrm{mg} / \mathrm{kg}$ excluded small bowel CD [46]. In subsequent studies, however, fCal was an inadequate biomarker for inflammatory lesions in the small bowel, with a sensitivity of $59-70 \%$ and a specificity of $44-71 \%[38,47]$. In a recent meta-analysis that included 463 patients with a clinically relevant indication for performing $\mathrm{CE}, \mathrm{fCal}>50 \mathrm{mg} / \mathrm{kg}$ had a sensitivity and specificity of $83 \%$ and $53 \%$ for detection of small bowel CD [48].

Few studies have examined the benefit of performing CE after ileocolonoscopy. In a study comparing CE with ileocolonoscopy in patients with suspected small bowel CD, diagnostic yields for the terminal ileum and cecum were comparable [49]. A total of 25 patients were diagnosed with small bowel CD, of whom 11 were diagnosed based solely on the result of CE (lesions isolated in the proximal small bowel in 3). This study suggests that ileocolonoscopy and CE are complementary modalities for diagnosing CD in the terminal ileum, that ileocolonoscopy should be the primary diagnostic modality, and that CE is of benefit in patients with a negative ileocolonoscopy. In contrast, in a study of 93 patients with suspected CD, limited diagnostic information was gained with

Table 3 Studies comparing the sensitivity and specificity of capsule endoscopy for diagnosing small bowel CD with different gold standards

\begin{tabular}{|c|c|c|c|c|c|c|}
\hline Studies & Study design & $\begin{array}{l}\text { Diagnostic } \\
\text { lesions at } \mathrm{CE}\end{array}$ & Gold standard & $\mathrm{n}$ & Sensitivity (\%) & Specificity (\%) \\
\hline Dubcenco, 2005 [34] & Prospective & Ulcerations & $\begin{array}{l}\text { Biopsy from the } \\
\text { terminal ileum }\end{array}$ & 39 & 90 & 100 \\
\hline Albert, 2005 [29] & Prospective & Ulcerations & Follow-up & 25 & 92 & 100 \\
\hline Solem, 2008 [30] & Prospective & Unknown & $\begin{array}{l}\text { Consensus based on } \\
\text { the results of CE, CT, } \\
\text { SB radiography and IC }\end{array}$ & 27 & 83 & 53 \\
\hline Tukey, 2009 [88] & $\begin{array}{l}\text { Retrospective analysis } \\
\text { of CEs performed after } \\
\text { a negative IC and SB } \\
\text { radiography }\end{array}$ & Ulcerations & Follow-up & 102 & 77 & 89 \\
\hline Jensen, 2011 [7] & Prospective & Ulcerations & IC & 69 & 100 & 91 \\
\hline
\end{tabular}


$\mathrm{CE}$ in patients with $\mathrm{CD}$ in the colon and a normal terminal ileum, or patients with non-complicated $\mathrm{CD}$ in the terminal ileum detected at ileocolonoscopy [50].

\section{Diagnostic algorithm in suspected CD}

Ileocolonoscopy is the accepted gold standard for diagnosing CD located in the colon and terminal ileum and is currently recommended as the initial diagnostic modality in suspected CD [51]. In the majority of patients, CD is located within the reach of the colonoscope, whereas $\mathrm{CD}$ isolated in the upper small bowel, without involvement of the colon or terminal ileum, is uncommon [52]. At the present time, international guidelines recommend small bowel imaging in all patients with a clinical suspicion of $C D$, irrespective of the findings at ileocolonoscopy (evidence level 5, recommendation grad D), and CE should be the first-line investigation in patients without obstructive symptoms (Fig. 2A) [8,26,51]. In patients with obstructive symptoms or known stenosis, crosssectional imaging, such as MRE or CTE is preferred. However, additional studies determining the benefit and clinical impact of performing CE in adult patients with suspected CD after ileocolonoscopy are warranted. Future guidelines should also consider noninvasive markers such as fCal as a tool for selecting patients for ileocolonoscopy. An alternative algorithm based on a single prospective study of fCal, ileocolonoscopy, CE and cross-sectional imaging in suspected CD has previously been published by our group [50]. Patients with an elevated fCal should undergo colonoscopy, including a persistent attempt to intubate the terminal ileum. In patients with a normal ileocolonoscopy or non-complicated CD in the colon and/or terminal ileum, small bowel imaging provides little extra information compared to ileoscopy alone. Small bowel imaging is primarily indicated if ileoscopy is not achieved and $\mathrm{CE}$ is the preferred first-line imaging technique. MRE and
CTE are complimentary modalities preferably used in patients with stenosis detected at ileocolonoscopy or suspicion of extra-intestinal disease complications. Additional studies are required to validate this diagnostic approach.

\section{Known CD}

In the majority of patients, the phenotype of $\mathrm{CD}$ changes over time from mainly inflammatory lesions at the time of diagnosis to stricturing or penetrating disease [53]. Correspondingly, a large number of patients require surgery within the first 10 years of diagnosis $[53,54]$, and the utility of $\mathrm{CE}$ is hampered by the risk of capsule retention. In a comprehensive literature review, capsule retention occurred in $2.6 \%$ of patients examined for suspected or known CD [55], and retention rates of $4-13 \%$ have been reported in patients with symptomatic CD [56].

In the meta-analysis by Dionisio et al, the diagnostic yield of CE in patients with known CD was superior to that of small bowel radiography (71\% vs. $36 \%, \mathrm{P}<0.00001, \mathrm{n}=224)$ and $\mathrm{CT}$ enterography ( $71 \%$ vs. $39 \%, \mathrm{P}<0.0001, \mathrm{n}=66$ ) [28]. There was a trend towards a higher yield compared to ileocolonoscopy ( $70 \%$ vs. $57 \%, \mathrm{P}=0.07, \mathrm{n}=158$ ), whereas $\mathrm{MRE}$ had an equally high diagnostic yield $(\mathrm{P}=0.65)$. It should be emphasized, however, that original studies excluded patients with a radiological suspicion of small bowel stenosis. Therefore, CE is superior to cross-sectional imaging and ileocolonoscopy in a subgroup of patients with non-stricturing $\mathrm{CD}$, which tends to favor the most sensitive modality for mucosal inflammation, i.e. endoscopy over cross-sectional imaging.

There is a lack of prospective studies directly comparing the feasibility, sensitivity and specificity of CE with that of crosssectional imaging in patients with known $C D$. In retrospective studies involving this group of patients, CE was safe and added significant diagnostic information in a large number of

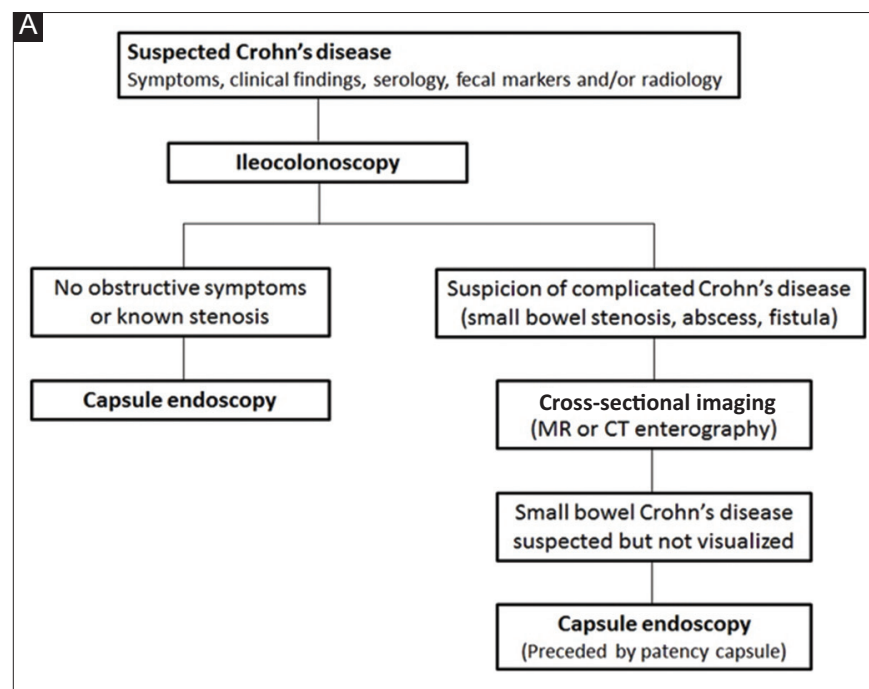

B

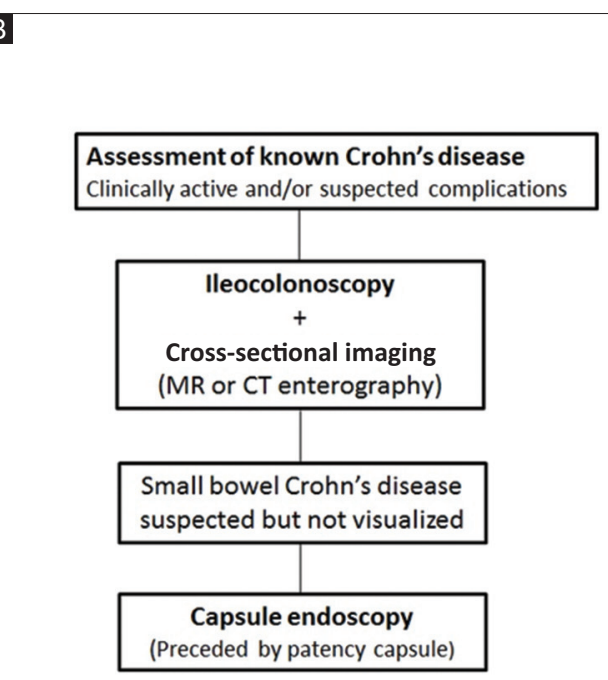

Figure 2 The internationally recommended diagnostic algorithm in patients with (A) suspected Crohn's disease and (B) symptomatic known Crohn's disease $[8,26]$ 
patients, with a subsequent impact on clinical decision [38,57]. Compared to cross-sectional imaging, CE detects significantly more lesions in the proximal small bowel, primarily in the form of mild lesions [7,58]. The clinical significance of this diagnostic information has previously been debated [26]. However, a recent retrospective study of 108 patients with known CD found jejunal lesions in more than half of the patients, and the presence of proximal lesions was an independent risk factor for future clinical relapse (adjusted hazard ratio of 1.99; 95\% CI, 1.10-3.61; $\mathrm{P}=0.02$ ) [59]. Hence, the greater sensitivity of $\mathrm{CE}$ for proximal small bowel lesions compared to cross-sectional imaging seems to have prognostic importance and an impact on clinical decision-making. Furthermore, the discomfort experienced by the patient is significantly lower with CE compared to cross-sectional imaging, and $78 \%$ of patients would prefer this modality as a future examination $[7,60]$.

\section{Diagnostic algorithm in known CD}

In patients with symptomatic $\mathrm{CD}$, current guidelines recommend dedicated small imaging, irrespective of the findings at ileocolonoscopy, because the detection of lesions may have prognostic and therapeutic implications (Fig. 2B) [8,51]. In this group of patients, the prevalence of disease complications is high, and cross-sectional imaging is the preferred modality for diagnosing inflammatory lesions and strictures beyond the reach of the colonoscope, as well as fistulas and abscesses. CE should be reserved as a secondline modality in patients with unexplained symptoms after ileocolonoscopy and cross-sectional imaging, if the symptoms require further evaluation and findings are expected to alter medical treatment. CE should be preceded by either crosssectional imaging or examination with a patency capsule to avoid capsule retention $[8,26]$.

\section{Assessment of disease activity and mucosal healing}

There are currently two validated indexes available for assessing the disease location and severity of small bowel CD with CE (Table 4). The Lewis score evaluates three small bowel segments for the parameters villous appearance, ulcers and stenosis [61]. The Capsule Endoscopy Crohn's Disease Activity Index. (CECDAI) evaluates the proximal and distal small bowel for the parameters inflammatory lesions, disease extension and stenosis [62]. A software application for calculation of the Lewis score has been incorporated into the RAPID Reader platform for Pillcam SB. The following cutoffs have been proposed: $<135$, normal small bowel or clinically insignificant inflammation; 135-79, mild disease activity; and $>790$, moderate to severe disease [61]. The CECDAI is simpler to calculate, but cutoffs for endoscopic remission and different disease severities have not been properly established. However, there is a good correlation between the two indexes $(r=0.63$, $\mathrm{P}<0.0001)$, and in a retrospective and unblinded single reader analysis, CECDAI levels of 3.8 and 5.8 corresponded to Lewis scores of 135 and 790, respectively [40,63].

Although the Lewis score and CECDAI are able to quantify the severity of mucosal inflammation, it should be emphasized that they cannot be applied as diagnostic tools in general, because the parameters included in the scores are not disease specific. However, in a retrospective study of 95 patients with suspected CD, a normal ileocolonoscopy and follow up as gold standard, a Lewis score $\geq 135$ had a sensitivity and specificity of $89.5 \%$ and $78.9 \%$, respectively, for the diagnosis of CD [64]. A Lewis score $<135$ excluded CD with a negative predictive value of $92 \%$. Hence, in patients with suspected CD, a normal Lewis score virtually excludes the diagnosis. In patients who have findings consistent with $\mathrm{CD}$, i.e. multiple ulcerations, both the Lewis score and CECDAI may be applied to quantify the disease severity and location.

A few studies have examined the applicability of CE as a tool for monitoring treatment response and mucosal healing in small bowel CD. Currently, however, there is no validated criterion for mucosal healing with $\mathrm{CE}$ [8]. Equivalent to ileocolonic $\mathrm{CD}$, achieving clinical remission is only paralleled by mucosal healing in a minority of patients with small bowel CD. Hence, CE may serve as an objective tool for monitoring the treatment response and mucosal healing $[40,65,66]$. The clinical benefit of using $\mathrm{CE}$ as a disease monitoring tool with treatment escalation in patients who have not achieved mucosal healing needs to be shown. No studies have compared $\mathrm{CE}$ to cross-sectional imaging in relation to these matters.

\section{Post-surgical recurrence}

One year after surgical resection of the terminal ileum because of $\mathrm{CD}$, inflammatory lesions can be detected endoscopically in $73-93 \%$ of patients, although clinical recurrence only occurs in $20-37 \%$ at this point in time $[67,68]$. Detection of post-surgical recurrence may have important therapeutic implications. Boureille et al compared CE to ileocolonoscopy for the detection of post-surgical recurrence in 32 patients a median of 6 months after an ileocolonic resection [69]. With a composite gold standard including both the results of ileocolonoscopy and CE analyzed by two observers, the sensitivity of CE was inferior to that of ileocolonoscopy for the detection of disease recurrence in the neoterminal ileum (62-76\% vs. $90 \%$, respectively). However, CE detected inflammatory lesions outside the reach of the colonoscope in two thirds of patients. The severity of lesions detected with ileocolonoscopy and CE correlated significantly $(r=0.54-0.64, \mathrm{P}<0.05)$. In a similar study by Pons Beltran et al, both endoscopic procedures were performed in 22 patients 6-12 months after ileocolonic resection [70]. Ileocolonoscopy and $\mathrm{CE}$ detected post-surgical recurrence in the neoterminal ileum in 6 and 15 patients, respectively. Lesions beyond the reach of the colonoscope were detected in 13 patients with $\mathrm{CE}$, including 3 patients without involvement of the neoterminal ileum. All patients preferred CE over ileocolonoscopy.

Hence, data regarding the sensitivity of CE for the detection of post-surgical recurrence in the neoterminal ileum are 
Table 4 Validated indexes for determining the severity of Crohn's disease in the small bowel with capsule endoscopy

A: Lewis score

Villous appearance (for each small bowel tertile*)

Number: normal (0) or edematous (1)

Longitudinal extent**: short segment (8), long segment (12) or whole tertile (20)

Descriptor: singe (1), patchy (14) or diffuse (17)

Ulcer (for each small bowel tertile*)

Number: no ulcers (0), one ulcer (3), two to seven ulcers (5) or eight or more ulcers (10)

Longitudinal extent**: short segment (5), long segment (10) or whole tertile (15)

Descriptor: $<1 / 4(9), 1 / 4-1 / 2(12)$ or $>1 / 2$ (18) of the capsule picture occupied by the largest ulcer

Stenosis

Number: none (0), single (14) or multiple (20)

Ulcerated (24) or non-ulcerated (2)

Traversed (7) or not traversed (10) by the capsule

Total Lewis score $=$ score of the worst affected tertile

(villous appearance $\times$ extent $\times$ descriptor + ulcer number $\times$ extent $\times$ size $)+$ stenosis number $\times$ ulcerated $\times$ traversed

${ }^{\star}$ The small bowel is divided into tertiles according to the transit time

** Short segment: $<10 \%$ of the tertile; long segment: $11-50 \%$ of the tertile; whole segment: $>50 \%$ of the tertile

B: Capsule endoscopy Crohn's disease activity index (CECDAI)

A. Inflammation score

0 = None; 1 = Mild to moderate edema/hyperemia/denudation; 2 = Severe edema/hyperemia/denudation; 3 = Bleeding, exudate, aphthae, erosion, small ulcer $(<0.5 \mathrm{~cm}) ; 4=$ Moderate ulcer $(0.5-2 \mathrm{~cm})$, pseudopolyp; $5=$ Large ulcer $(>2 \mathrm{~cm})$

B. Extent of disease score

$0=$ None; 1 = Focal disease (single segment); 2 = Patchy disease (multiple segments); 3 = Diffuse disease

C. Narrowing (stricture)

0 = None; 1 = Single-passed; 2 = Multiple-passed; 3 = Obstruction

Total score $=(\mathrm{A} 1 \times \mathrm{B} 1+\mathrm{C} 1)+(\mathrm{A} 2 \times \mathrm{B} 2+\mathrm{C} 2)^{*}$

${ }^{\star}$ The small bowel is divided into a proximal (1) and distal (2) segment according to the transit time

conflicting, and the applicability of $\mathrm{CE}$ in this situation remains to be clarified. Currently, ileocolonoscopy is considered the gold standard, and the Rutgeerts's score is recommended for determining the disease severity [26]. Lesions of increasing severity found on ileocolonoscopy are a strong predictor for clinical recurrence, and current guidelines of the European Crohn's and Colitis Organisation recommend ileocolonoscopy 6-12 months after surgery in cases where treatment decisions may be affected [26]. In patients without obstructive symptoms who are unwilling to undergo ileocolonoscopy, CE seems to be a safe and patient-friendly alternative with a high diagnostic yield for $\mathrm{CD}$ recurrence in both the proximal and distal small bowel.

\section{Small bowel patency}

If a small bowel stenosis is not firmly excluded, the Pillcam patency capsule (Medtronic, Dublin, Ireland) can be used to confirm small bowel patency before performing CE. The patency capsule is a dissolvable capsule with the same size as the Pillcam SB3 capsule $(26 \times 11 \mathrm{~mm})$. It is composed of a lactose body mixed with barium and a radio frequency identification tag. At each end, the patency capsule has a timer plug that is designed to erode after $30 \mathrm{~h}$, resulting in disintegration of the capsule, and it has been stated that all patency capsules are dissolved within $72 \mathrm{~h} \mathrm{[71].} \mathrm{CE} \mathrm{is} \mathrm{considered} \mathrm{safe} \mathrm{if} \mathrm{the} \mathrm{patency}$ capsule is excreted before $30 \mathrm{~h}$, an intact capsule is excreted after $30 \mathrm{~h}$, or passage to the colon of an intact patency capsule has been radiologically confirmed.

Herrerias et al evaluated the Pillcam patency capsule in 106 patients with radiographic evidence of a small bowel stricture [72]. Small bowel patency was confirmed in 59, and none of these patients experienced capsule retention during a subsequent CE. No severe adverse events could be attributed to the patency capsule. Furthermore, Yadav et al concluded that the Pillcam patency capsule and radiological examination were equally reliable for excluding small bowel obstruction or strictures [73]. Hence, available studies suggest that the Pillcam patency capsule is equal to radiology and is a safe method for testing small bowel patency before CE, even in patients with 
a radiologically verified stenosis. However, symptomatic and potentially severe capsule retention with the Pillcam patency capsule has been reported [74,75]. In a recent multicenter case series of 1615 patients examined with the Pillcam patency capsule, $20(1.2 \%)$ symptomatic cases of capsule retention were identified [76]. One patient required surgery; all other patients with a retained patency capsule in the small bowel resolved spontaneously or after corticosteroid therapy. Hence, symptomatic patency capsule retention is uncommon and the prognosis is good.

\section{Reading protocols}

A significant limitation with $\mathrm{CE}$ is the time-consuming video analysis. In previous series, reading times above 40-50 min were reported [77]; thus, ways to reduce reading times without affecting the diagnostic accuracy would be helpful in clinical practice. For CD in particular, increasing the viewing speed may be feasible, because this disease is characterized by multiple lesions that are most often widespread in the small bowel.

Given Imaging's RAPID Reader enables alterations of the viewing mode from single to dual or quad view, and the frame rate can be adjusted from 5 to 40 frames per second $(\mathrm{fr} / \mathrm{sec})$. Günther et al compared single view at a speed of $10 \mathrm{fr} / \mathrm{sec}$ with quad view at $20 \mathrm{fr} / \mathrm{sec}$ [78]. The mean reading time was reduced from 22 down to $12 \mathrm{~min}$, and detection rates of angioectasias, erosions, ulcers, and polyps were significantly lower with quad view. However, in patients with suspected or known CD, overlooked lesions did not change the result of the examination. Recently, Nakamura et al compared single view, dual view and quad view at different frame rates, using a small bowel video sequence with 60 pathological images of small bowel angioectasias [79]. Increasing the frame rate from 10 to 15,25 and $40 \mathrm{fr} / \mathrm{sec}$ resulted in a $33 \%, 60 \%$, and $72 \%$ reduction in playing time, respectively, but at the expense of a drop in the number of lesions detected. Altering the viewing mode had no effect on the reading time for any given frame rate, but the detection rate was significantly higher with dual and quad view compared to single view. The authors conclude that the optimal combination for a high detection rate is $10 \mathrm{fr} / \mathrm{sec}$ using dual or quad view.

Another way to decrease reading times is by reducing the number of images presented to the capsule endoscopist. The quick view function provided by Given Imaging's RAPID Reader filters the number of images shown. With a sampling rate of $10 \%$ (default setting), $10 \%$ of images from the original videos is shown. Images are filtered according to a specific algorithm developed by the manufacturer, and sampling rates between $2 \%$ and $80 \%$ can be chosen. Shiotani et al examined how different sampling rates affect the detection rates of quick view CE [80]. A variety of preselected lesions were included in the study. With sampling rates of 5\%, 15\%, 25\% and 35\%, 61\%,74\%, 93\% and $98 \%$ of lesions were detected. With a $25 \%$ sampling rate, only $7 \%$ of lesions were missed, and the reading time was reduced by approximately $50 \%$. This setting was considered a proper trade- off between reading times and detection rates. Koulaouzidis et al studied 81 patients with suspected or known CD [81]. A total of 155 and 71 ulcerations were detected with $\mathrm{CE}$ and quick view $\mathrm{CE}$, respectively, with a $35 \%$ sampling rate, corresponding to a miss rate of $54 \%$. In patients with suspected or known CD, quick view $\mathrm{CE}$ was false negative (i.e. no or non-specific lesions or $<3$ ulcerations) in $1(7 \%)$ and $8(10 \%)$ patients, respectively. In a study by our group, including 40 patients with suspected $\mathrm{CD}$, standard view $\mathrm{CE}$ visualized 171 small bowel ulcerations, compared to 102 lesions detected with quick view CE (miss rate $40 \%, \mathrm{P}=0.02$ ) [82]. However, with ileocolonoscopy and standard view $\mathrm{CE}$ as gold standard, quick view $\mathrm{CE}$ diagnosed 15 of 16 patients with small bowel $\mathrm{CD}$, corresponding to a sensitivity of $94 \%$, while 39 out of 40 patients were classified correctly overall (diagnostic accuracy 98\%). Reading times varied from 5-18 min (median 10).

Hence, the available software for analyzing CEs allows for faster reading times, either by increasing the frame rate, with or without altering the viewing mode, or using the quick view function. However, a reduced reading time comes at a cost, as increasing the speed results in lower detection rates. Data on patients with suspected or known CD are scarce, but available data suggest that, despite the fact that fewer lesions are detected, the overall sensitivity for CD is acceptable, and the quick view function may serve as a method for screening for CD lesions, especially in patients with suspected CD. Additional studies in patients with suspected or known CD are warranted and a generally accepted reading protocol has not yet been established [83].

\section{Panenteric CE}

Using CE for evaluating both the small bowel and colon in a single noninvasive examination is an attractive diagnostic approach. Pillcam colon CE (PCCE) was introduced in 2006 and soon a panenteric capsule endoscope will be available: i.e. the small bowel colon (SBC) capsule (Medtronic, Dublin, Ireland). The SBC capsule is similar to the Pillcam COLON2 in all its hardware components, but it is designed to provide complete coverage of the small bowel and colon [84]. Until now, few studies have evaluated this modality for diagnosing $\mathrm{CD}$ in the colon and small bowel.

Performing CE of the colon requires optimal cleansing, and the European Society of Gastrointestinal Endoscopy currently recommends a regimen consisting of $4 \mathrm{~L}$ of PEG in two divided doses and sodium phosphate (Phosphoral) as booster [85]. In a prospective study of patients with known $\mathrm{CD}$, the number who reported discomfort was significantly lower with PCCE compared to ileocolonoscopy [86]. PCCE had a sensitivity of $86 \%$ for detection of ulcerations in the colon and terminal ileum, and lesions outside the reach of the colonoscope were detected in $15 \%$ of patients. There was a moderate correlation between PCCE and ileocolonoscopy for the assessment of disease severity. In a prospective study of 38 pediatric patients with CD, PCCE was compared to MRE and small intestine contrast ultrasonography (SICUS) [87]. The sensitivity of PCCE 
for detecting colonic inflammation was $89 \%$ and the specificity was $100 \%$. In the small bowel, PCCE had $90 \%$ sensitivity and $94 \%$ specificity. The diagnostic accuracies of MRE and SICUS were slightly lower compared to PCCE, although the differences were not statistically significant. The tolerability of PCCE was superior compared to ileocolonoscopy, and the interobserver agreement was excellent $(\kappa=0.91)$.

In a recent study, Leighton et al compared the diagnostic yield of the SBC capsule with ileocolonoscopy in 66 patients with clinically active CD [84]. The per-subject diagnostic yield for CD lesions was $83.3 \%$ for the SBC capsule and $69.7 \%$ for ileocolonoscopy (incremental yield 13.6\%, 95\% CI 2.6$24.7 \%$ ). A greater percentage of active lesions was detected in each evaluated segment by the SBC capsule as compared with ileocolonoscopy, and the overall per-segment diagnostic yield was $40.6 \%$ for the SBC capsule and $32.7 \%$ for ileocolonoscopy (incremental yield 7.9\%, 95\% CI 3.3-12.4\%).

Hence, preliminary data suggest that $\mathrm{CE}$ is a feasible diagnostic modality in patients examined for non-obstructive $\mathrm{CD}$. Additional studies are warranted to evaluate panenteric CE for diagnosing $\mathrm{CD}$ and to compare the method with ileocolonoscopy and radiological modalities in terms of patient-experienced discomfort, complications and interobserver agreement.

\section{Concluding remarks}

$\mathrm{CE}$ has revolutionized the diagnosis and monitoring of small bowel CD. The procedure is patient-friendly and noninvasive and, compared to cross-sectional imaging, $\mathrm{CE}$ allows a direct and detailed evaluation of the entire small bowel mucosa with a high sensitivity for the earliest lesions of CD. Today, CE is the leading modality for visualizing the small bowel in suspected CD, and validated activity indices are available for the follow up of patients with established CD. $\mathrm{CE}$ of the entire gastrointestinal tract was recently introduced as a new diagnostic approach, and preliminary data show high sensitivity, specificity, interobserver agreement and tolerability compared to ileocolonoscopy. There are important limitations, however, of which capsule retention is the main concern. Furthermore, a diagnostic criterion for CD has never been validated and lesions detected by $\mathrm{CE}$ are not specific for CD. Hence, concern has been raised about a low specificity compared to other diagnostic modalities. Future studies should address important questions about the optimal bowel preparation for small bowel and panenteric CE, the selection of patients with suspected or known CD, the optimal reading protocol and the diagnostic performance of panenteric CE compared to cross-sectional imaging.

\section{References}

1. Chauhan SS, Manfredi MA, Abu Dayyeh BK, et al; ASGE Technology Committee. Enteroscopy. Gastrointest Endosc 2015;82:975-990.
2. Panes J, Bouhnik Y, Reinisch W, et al. Imaging techniques for assessment of inflammatory bowel disease: joint ECCO and ESGAR evidence-based consensus guidelines. J Crohns Colitis 2013;7:556-585.

3. Panés J, Bouzas R, Chaparro M, et al. Systematic review: the use of ultrasonography, computed tomography and magnetic resonance imaging for the diagnosis, assessment of activity and abdominal complications of Crohn's disease. Aliment Pharmacol Ther 2011;34:125-145.

4. Wang A, Banerjee S, Barth BA, et al; ASGE Technology Committee. Wireless capsule endoscopy. Gastrointest Endosc 2013;78:805-815.

5. Koulaouzidis A, Rondonotti E, Karargyris A. Small-bowel capsule endoscopy: a ten-point contemporary review. World J Gastroenterol 2013;19:3726-3746.

6. Greener T, Klang E, Yablecovitch D, et al; Israeli IBD Research Nucleus (IIRN). The impact of magnetic resonance enterography and capsule endoscopy on the re-classification of disease in patients with known Crohn's disease: a prospective Israeli IBD Research Nucleus (IIRN) Study. J Crohns Colitis 2016;10:525-531.

7. Jensen MD, Nathan T, Rafaelsen SR, Kjeldsen J. Diagnostic accuracy of capsule endoscopy for small bowel Crohn's disease is superior to that of MR enterography or CT enterography. Clin Gastroenterol Hepatol 2011;9:124-129.

8. Pennazio M, Spada C, Eliakim R, et al. Small-bowel capsule endoscopy and device-assisted enteroscopy for diagnosis and treatment of small-bowel disorders: European Society of Gastrointestinal Endoscopy (ESGE) Clinical Guideline. Endoscopy 2015;47:352-376.

9. Mitselos IV, Christodoulou DK, Katsanos KH, Tsianos EV. Role of wireless capsule endoscopy in the follow-up of inflammatory bowel disease. World J Gastrointest Endosc 2015;7:643-651.

10. Whiting P, Rutjes AW, Reitsma JB, Bossuyt PM, Kleijnen J. The development of QUADAS: a tool for the quality assessment of studies of diagnostic accuracy included in systematic reviews. BMC Med Res Methodol 2003;3:25.

11. Keuchel M, Hagenmüller F, Tajiri H. Video capsule endoscopy. 1 ed: Springer-Verlag Berlin Heidelberg; 2014.

12. Cave DR, Fleischer DE, Leighton JA, et al. A multicenter randomized comparison of the Endocapsule and the Pillcam SB. Gastrointest Endosc 2008:68:487-494.

13. Hartmann D, Eickhoff A, Damian U, Riemann JF. Diagnosis of small-bowel pathology using paired capsule endoscopy with two different devices: a randomized study. Endoscopy 2007;39:10411045.

14. Pioche M, Gaudin JL, Filoche B, et al; French Society of Digestive Endoscopy. Prospective, randomized comparison of two smallbowel capsule endoscopy systems in patients with obscure GI bleeding. Gastrointest Endosc 2011;73:1181-1188.

15. Choi EH, Mergener K, Semrad C, et al. A multicenter, prospective, randomized comparison of a novel signal transmission capsule endoscope to an existing capsule endoscope. Gastrointest Endosc 2013;78:325-332.

16. Pioche M, Vanbiervliet G, Jacob P, et al; French Society of Digestive Endoscopy (SFED). Prospective randomized comparison between axial- and lateral-viewing capsule endoscopy systems in patients with obscure digestive bleeding. Endoscopy 2014;46:479-484.

17. Dolak W, Kulnigg-Dabsch S, Evstatiev R, Gasche C, Trauner M, Püspök A. A randomized head-to-head study of small-bowel imaging comparing MiroCam and EndoCapsule. Endoscopy 2012;44:1012-1020.

18. Rokkas T, Papaxoinis K, Triantafyllou K, Pistiolas D, Ladas SD. Does purgative preparation influence the diagnostic yield of small bowel video capsule endoscopy?: A meta-analysis. Am J Gastroenterol 2009;104:219-227.

19. Koulaouzidis A, Giannakou A, Yung DE, Dabos KJ, Plevris JN. Do 
prokinetics influence the completion rate in small-bowel capsule endoscopy? A systematic review and meta-analysis. Curr Med Res Opin 2013;29:1171-1185.

20. Kotwal VS, Attar BM, Gupta S, Agarwal R. Should bowel preparation, antifoaming agents, or prokinetics be used before video capsule endoscopy? A systematic review and meta-analysis. Eur J Gastroenterol Hepatol 2014;26:137-145.

21. Belsey J, Crosta C, Epstein O, et al. Meta-analysis: efficacy of small bowel preparation for small bowel video capsule endoscopy. Curr Med Res Opin 2012;28:1883-1890.

22. Wu L, Cao Y, Liao C, Huang J, Gao F. Systematic review and meta-analysis of randomized controlled trials of Simethicone for gastrointestinal endoscopic visibility. Scand J Gastroenterol 2011;46:227-235.

23. Bourreille A, Ignjatovic A, Aabakken L, et al; World Organisation of Digestive Endoscopy (OMED) and the European Crohn's and Colitis Organisation (ECCO). Role of small-bowel endoscopy in the management of patients with inflammatory bowel disease: an international OMED-ECCO consensus. Endoscopy 2009;41:618-637.

24. Maiden L, Thjodleifsson B, Seigal A, et al. Long-term effects of nonsteroidal anti-inflammatory drugs and cyclooxygenase-2 selective agents on the small bowel: a cross-sectional capsule enteroscopy study. Clin Gastroenterol Hepatol 2007;5:1040-1045.

25. Goldstein JL, Eisen GM, Lewis B, Gralnek IM, Zlotnick S, Fort JG. Video capsule endoscopy to prospectively assess small bowel injury with celecoxib, naproxen plus omeprazole, and placebo. Clin Gastroenterol Hepatol 2005;3:133-141.

26. Annese V, Daperno M, Rutter MD, et al; European Crohn's and Colitis Organisation. European evidence based consensus for endoscopy in inflammatory bowel disease. J Crohns Colitis 2013;7:982-1018.

27. Mow WS, Lo SK, Targan SR, et al. Initial experience with wireless capsule enteroscopy in the diagnosis and management of inflammatory bowel disease. Clin Gastroenterol Hepatol 2004;2:31-40.

28. Dionisio PM, Gurudu SR, Leighton JA, et al. Capsule endoscopy has a significantly higher diagnostic yield in patients with suspected and established small-bowel Crohn's disease: a meta-analysis. Am J Gastroenterol 2010;105:1240-1248.

29. Albert JG, Martiny F, Krummenerl A, et al. Diagnosis of small bowel Crohn's disease: a prospective comparison of capsule endoscopy with magnetic resonance imaging and fluoroscopic enteroclysis. Gut 2005;54:1721-1727.

30. Solem CA, Loftus EV Jr, Fletcher JG, et al. Small-bowel imaging in Crohn's disease: a prospective, blinded, 4-way comparison trial. Gastrointest Endosc 2008;68:255-266.

31. Gölder SK, Schreyer AG, Endlicher E, et al. Comparison of capsule endoscopy and magnetic resonance (MR) enteroclysis in suspected small bowel disease. Int J Colorectal Dis 2006;21:97-104.

32. Eliakim R, Suissa A, Yassin K, Katz D, Fischer D. Wireless capsule video endoscopy compared to barium follow-through and computerised tomography in patients with suspected Crohn's disease-final report. Dig Liver Dis 2004;36:519-522.

33. Efthymiou A, Viazis N, Vlachogiannakos J, et al. Wireless capsule endoscopy versus enteroclysis in the diagnosis of small-bowel Crohn's disease. Eur J Gastroenterol Hepatol 2009;21:866-871.

34. Dubcenco E, Jeejeebhoy KN, Petroniene R, et al. Capsule endoscopy findings in patients with established and suspected small-bowel Crohn's disease: correlation with radiologic, endoscopic, and histologic findings. Gastrointest Endosc 2005;62:538-544.

35. Katsinelos P, Fasoulas K, Beltsis A, et al. Diagnostic yield and clinical impact of wireless capsule endoscopy in patients with chronic abdominal pain with or without diarrhea: a Greek multicenter study. Eur J Intern Med 2011;22:e63-e66.

36. De Bona M, Bellumat A, Cian E, Valiante F, Moschini A, De Boni M. Capsule endoscopy findings in patients with suspected
Crohn's disease and biochemical markers of inflammation. Dig Liver Dis 2006;38:331-335.

37. Yang L, Ge ZZ, Gao YJ, et al. Assessment of capsule endoscopy scoring index, clinical disease activity, and C-reactive protein in small bowel Crohn's disease. J Gastroenterol Hepatol 2013;28:829-833.

38. Kopylov U, Nemeth A, Koulaouzidis A, et al. Small bowel capsule endoscopy in the management of established Crohn's disease: clinical impact, safety, and correlation with inflammatory biomarkers. Inflamm Bowel Dis 2015;21:93-100.

39. Mosli MH, Zou G, Garg SK, et al. C-reactive protein, fecal calprotectin, and stool lactoferrin for detection of endoscopic activity in symptomatic inflammatory bowel disease patients: a systematic review and meta-analysis. Am J Gastroenterol 2015;110:802-819; quiz 820.

40. Kopylov U, Yablecovitch D, Lahat A, et al. Detection of small bowel mucosal healing and deep remission in patients with known small bowel Crohn's disease using biomarkers, capsule endoscopy, and imaging. Am J Gastroenterol 2015;110:1316-1323.

41. van Rheenen PF, Van de Vijver E, Fidler V. Faecal calprotectin for screening of patients with suspected inflammatory bowel disease: diagnostic meta-analysis. BMJ 2010;341:c3369.

42. Menees SB, Powell C, Kurlander J, Goel A, Chey WD. A metaanalysis of the utility of C-reactive protein, erythrocyte sedimentation rate, fecal calprotectin, and fecal lactoferrin to exclude inflammatory bowel disease in adults with IBS. Am J Gastroenterol 2015;110:444-454.

43. Schoepfer AM, Beglinger C, Straumann A, et al. Fecal calprotectin correlates more closely with the Simple Endoscopic Score for Crohn's disease (SES-CD) than CRP, blood leukocytes, and the CDAI. Am J Gastroenterol 2010;105:162-169.

44. Sipponen T, Savilahti E, Kolho KL, Nuutinen H, Turunen U, Färkkilä M. Crohn's disease activity assessed by fecal calprotectin and lactoferrin: correlation with Crohn's disease activity index and endoscopic findings. Inflamm Bowel Dis 2008;14:40-46.

45. Jensen MD, Kjeldsen J, Nathan T. Fecal calprotectin is equally sensitive in Crohn's disease affecting the small bowel and colon. Scand J Gastroenterol 2011;46:694-700.

46. Koulaouzidis A, Douglas S, Rogers MA, Arnott ID, Plevris JN. Fecal calprotectin: a selection tool for small bowel capsule endoscopy in suspected IBD with prior negative bi-directional endoscopy. Scand J Gastroenterol 2011;46:561-566.

47. Sipponen T, Haapamäki J, Savilahti E, et al. Fecal calprotectin and S100A12 have low utility in prediction of small bowel Crohn's disease detected by wireless capsule endoscopy. Scand J Gastroenterol 2012;47:778-784.

48. Kopylov U, Yung DE, Engel T, et al. Fecal calprotectin for the prediction of small-bowel Crohn's disease by capsule endoscopy: a systematic review and meta-analysis. Eur J Gastroenterol Hepatol 2016;28:1137-1144.

49. Leighton JA, Gralnek IM, Cohen SA, et al. Capsule endoscopy is superior to small-bowel follow-through and equivalent to ileocolonoscopy in suspected Crohn's disease. Clin Gastroenterol Hepatol 2014;12:609-615.

50. Jensen MD, Nathan T, Rafaelsen SR, Kjeldsen J. Ileoscopy reduces the need for small bowel imaging in suspected Crohn's disease. Dan Med J 2012;59:A4491.

51. Van Assche G, Dignass A, Panes J, et al; European Crohn's and Colitis Organisation (ECCO). The second European evidencebased Consensus on the diagnosis and management of Crohn's disease: Definitions and diagnosis. J Crohns Colitis 2010;4:7-27.

52. Van Limbergen J, Russell RK, Drummond HE, et al. Definition of phenotypic characteristics of childhood-onset inflammatory bowel disease. Gastroenterology 2008;135:1114-1122.

53. Cosnes J, Cattan S, Blain A, et al. Long-term evolution of disease behavior of Crohn's disease. Inflamm Bowel Dis 2002;8:244-250. 
54. Frolkis AD, Dykeman J, Negrón ME, et al. Risk of surgery for inflammatory bowel diseases has decreased over time: a systematic review and meta-analysis of population-based studies. Gastroenterology 2013;145:996-1006.

55. Liao Z, Gao R, Xu C, Li ZS. Indications and detection, completion, and retention rates of small-bowel capsule endoscopy: a systematic review. Gastrointest Endosc 2010;71:280-286.

56. Cheifetz AS, Kornbluth AA, Legnani P, et al. The risk of retention of the capsule endoscope in patients with known or suspected Crohn's disease. Am J Gastroenterol 2006;101:2218-2222.

57. Kalla R, McAlindon ME, Drew K, Sidhu R. Clinical utility of capsule endoscopy in patients with Crohn's disease and inflammatory bowel disease unclassified. Eur J Gastroenterol Hepatol 2013;25:706-713.

58. Voderholzer WA, Beinhoelzl J, Rogalla P, et al. Small bowel involvement in Crohn's disease: a prospective comparison of wireless capsule endoscopy and computed tomography enteroclysis. Gut 2005;54:369-373.

59. Flamant M, Trang C, Maillard O, et al. The prevalence and outcome of jejunal lesions visualized by small bowel capsule endoscopy in Crohn's disease. Inflamm Bowel Dis 2013;19:1390-1396.

60. Lahat A, Kopylov U, Amitai MM, et al. Magnetic resonance enterography or video capsule endoscopy - what do Crohn's disease patients prefer? Patient Prefer Adherence 2016;10:1043-1050.

61. Gralnek IM, Defranchis R, Seidman E, Leighton JA, Legnani P, Lewis BS. Development of a capsule endoscopy scoring index for small bowel mucosal inflammatory change. Aliment Pharmacol Ther 2008;27:146-154.

62. Gal E, Geller A, Fraser G, Levi Z, Niv Y. Assessment and validation of the new capsule endoscopy Crohn's disease activity index (CECDAI). Dig Dis Sci 2008;53:1933-1937.

63. Koulaouzidis A, Douglas S, Plevris JN. Lewis score correlates more closely with fecal calprotectin than Capsule Endoscopy Crohn's Disease Activity Index. Dig Dis Sci 2012;57:987-993.

64. Monteiro S, Boal Carvalho P, Dias de Castro F, et al. Capsule endoscopy: diagnostic accuracy of lewis score in patients with suspected Crohn's disease. Inflamm Bowel Dis 2015;21:2241-2246.

65. Hall B, Holleran G, Chin JL, et al. A prospective 52 week mucosal healing assessment of small bowel Crohn's disease as detected by capsule endoscopy. J Crohns Colitis 2014;8:1601-1609.

66. Efthymiou A, Viazis N, Mantzaris G, et al. Does clinical response correlate with mucosal healing in patients with Crohn's disease of the small bowel? A prospective, case-series study using wireless capsule endoscopy. Inflamm Bowel Dis 2008;14:1542-1547.

67. Rutgeerts P, Geboes K, Vantrappen G, Beyls J, Kerremans R, Hiele M. Predictability of the postoperative course of Crohn's disease. Gastroenterology 1990;99:956-963.

68. Olaison G, Smedh K, Sjödahl R. Natural course of Crohn's disease after ileocolic resection: endoscopically visualised ileal ulcers preceding symptoms. Gut 1992;33:331-335.

69. Bourreille A, Jarry M, D'Halluin PN, et al. Wireless capsule endoscopy versus ileocolonoscopy for the diagnosis of postoperative recurrence of Crohn's disease: a prospective study. Gut 2006;55:978-983.

70. Pons Beltran V, Nos P, Bastida G, et al. Evaluation of postsurgical recurrence in Crohn's disease: a new indication for capsule endoscopy? Gastrointest Endosc 2007;66:533-540.

71. Lewis BS. Expanding role of capsule endoscopy in inflammatory bowel disease. World J Gastroenterol 2008;14:4137-4141.

72. Herrerias JM, Leighton JA, Costamagna G, et al. Agile patency system eliminates risk of capsule retention in patients with known intestinal strictures who undergo capsule endoscopy. Gastrointest Endosc 2008;67:902-909.

73. Yadav A, Heigh RI, Hara AK, et al. Performance of the patency capsule compared with nonenteroclysis radiologic examinations in patients with known or suspected intestinal strictures. Gastrointest Endosc 2011;74:834-839.

74. Nemeth A, Kopylov U, Koulaouzidis A, et al. Use of patency capsule in patients with established Crohn's disease. Endoscopy 2016;48:373-379.

75. Rasmussen B, Nathan T, Jensen MD. Symptomatic patency capsule retention in suspected Crohn's disease. J Crohns Colitis 2016;10:1445-1447.

76. Kopylov U, Nemeth A, Cebrian A, et al. Symptomatic retention of the patency capsule: a multicenter real life case series. Endosc Int Open 2016;4:E964-E969.

77. Sidhu R, Sanders DS, Morris AJ, McAlindon ME. Guidelines on small bowel enteroscopy and capsule endoscopy in adults. Gut 2008;57:125-136.

78. Günther U, Daum S, Zeitz M, Bojarski C. Capsule endoscopy: comparison of two different reading modes. Int J Colorectal Dis 2012;27:521-525.

79. Nakamura M, Murino A, O’Rourke A, Fraser C. A critical analysis of the effect of view mode and frame rate on reading time and lesion detection during capsule endoscopy. Dig Dis Sci 2015;60:1743-1747.

80. Shiotani A, Honda K, Kawakami M, et al. Analysis of small-bowel capsule endoscopy reading by using Quickview mode: training assistants for reading may produce a high diagnostic yield and save time for physicians. J Clin Gastroenterol 2012;46:e92-e95.

81. Koulaouzidis A, Smirnidis A, Douglas S, Plevris JN. QuickView in small-bowel capsule endoscopy is useful in certain clinical settings, but QuickView with Blue Mode is of no additional benefit. Eur J Gastroenterol Hepatol 2012;24:1099-1104.

82. Halling ML, Nathan T, Kjeldsen J, Jensen MD. High sensitivity of quick view capsule endoscopy for detection of small bowel Crohn's disease. J Gastroenterol Hepatol 2014;29:992-996.

83. Koulaouzidis A, Toth E. Optimizing the interpretation of capsule endoscopic images: shortsighted or taking the long view? Dig Dis Sci 2015;60:1519-1521.

84. Leighton JA, Helper DJ, Gralnek IM, et al. Comparing diagnostic yield of a novel pan-enteric video capsule endoscope with ileocolonoscopy in patients with active Crohn's disease: a feasibility study. Gastrointest Endosc 2016 Sep 19. doi: 10.1016/j. gie.2016.09.009. [Epub ahead of print]

85. Spada C, Hassan C, Galmiche JP, et al; European Society of Gastrointestinal Endoscopy. Colon capsule endoscopy: European Society of Gastrointestinal Endoscopy (ESGE) Guideline. Endoscopy 2012;44:527-536.

86. D’Haens G, Löwenberg M, Samaan MA, et al. Safety and feasibility of using the second-generation pillcam colon capsule to assess active colonic Crohn's disease. Clin Gastroenterol Hepatol 2015;13:1480-1486.e3.

87. Oliva S, Cucchiara S, Civitelli F, et al. Colon capsule endoscopy compared with other modalities in the evaluation of pediatric Crohn's disease of the small bowel and colon. Gastrointest Endosc 2016;83:975-983.

88. Tukey M, Pleskow D, Legnani P, Cheifetz AS, Moss AC. The utility of capsule endoscopy in patients with suspected Crohn's disease. Am J Gastroenterol 2009;104:2734-2739. 